\title{
Macrosegregation in Dissimilar-Metal Fusion Welding
}

\author{
T. Soysal, S. Kou, D. Tat and T. Pasang
}

\begin{abstract}
Solute segregation on a macroscopic scale in a weld between two dissimilar metals or alloys has long been recognized, but fundamental understanding of macrosegregation in dissimilar-metal welding is still lacking. Two mechanisms for macrosegregation were proposed based on the liquidus temperature of the bulk weld metal, $T_{L W}$, relative to the liquidus temperature of metal $1, T_{L 1}$, and the liquidus temperature of metal $2, T_{L 2}$. According to the mechanisms, two distinctly different macrosegregation features can form. A "peninsula" of an unmixed metal 1 can form if $T_{L W}<T_{L 1}$. On the other hand, a "beach" of unmixed metal 2 irregular in shape can form if $T_{L W}>T_{L 2}$. To verify the mechanisms, a pure $\mathrm{Cu}$ sheet was butt welded to a low carbon steel sheet by gas-tungsten arc welding without a filler metal. Composition measurements were conducted inside and across the weld metal. A peninsula of unmixed steel and an irregular-shaped beach of unmixed $\mathrm{Cu}$ were observed, which verified the mechanisms. In addition, the bulk weld metal exhibited a layered structure caused by undercooling of the bulk weld pool into a metastable miscibility gap in the $\mathrm{Cu}$-Fe phase diagram. Macrosegregation in previous studies on laser- and electron-beam welding of $\mathrm{Cu}$ to steel or stainless steel was discussed in light of the findings in the present study.
\end{abstract}

T. Soysal and S. Kou are respectively Graduate Student and Professor in the Department of Materials Science and Engineering, the University of Wisconsin, Madison, WI 53706. D. Tat and T. Pasang are respectively Undergraduate Student and Professor in the Department of Mechanical Engineering, Auckland University of Technology, Auckland, New Zealand. 


\section{Introduction}

Dissimilar-metal welding, that is, welding two different metals or alloys together, has been an area of active research. Usually, dissimilar-metal fusion welding is feasible unless massive brittle intermetallic compounds form during solidification to cause severe cracking in the resultant weld metal, i.e., the fusion zone. Two examples of feasible dissimilar-metal fusion welding are well known, i.e., welding $\mathrm{Cu}$ to steel [1-5] or stainless steel [6-10], and welding stainless steel to steel or Ni-base alloys [11-14]. The first example is related to heat exchangers, where $\mathrm{Cu}$ tubes can enhance heat exchange because of their excellent thermal conductivity. The second example is related to power plants, where stainless steels or Ni-base alloys can offer superior corrosion resistance.

In dissimilar-metal welding, solute segregation on the macroscopic scale across the weld metal, called macrosegregation hereinafter, can occur because of the inherent composition difference between the two metals or alloys that are welded together. In addition to composition variations, features distinctly different from their surrounding bulk weld metal in microstructure as well as composition often exist near the fusion boundary and sometimes even far away from it. The features are much closer (in fact, often identical) to the base metals in composition than the surrounding weld metal.

Macrosegregation features such as base-metal-like "beaches", "peninsulas" and "islands" have been reported. Doody [11] welded carbon steel to stainless steel. The words "beach" and "island" were used for the first time to describe macrosegregation features. He observed basemetal-like beaches and islands on the carbon steel side of the weld. Omar [12] also welded carbon steel to stainless steel and observed beaches, peninsulas and islands on the carbon-steel side. The formation of these macrosegregation features was not understood. 
Macrosegregation occurs not only in dissimilar-metal welding but also in dissimilar-filler welding, that is, welding with a filler metal different from the workpiece in composition. Macrosegregation features have been reported to cause problems such as loss of toughness [8], hydrogen cracking [15-17], corrosion [18, 19] and stress-corrosion cracking [11, 18, 20, 21]. Thus, it is essential to understand how macrosegregation forms in welds.

Savage and coworkers [22, 23] first discovered macrosegregation near the fusion boundary in dissimilar-filler welding. An "unmixed zone" was found near the fusion boundary, that is, a beach. It was explained that a stagnant or laminar-flow layer of liquid base metal can exist at the pool boundary and solidify, without mixing with the bulk weld pool. Due to the viscosity of liquid metals, fluid flow in the weld pool diminishes near the pool boundary, where the fluid velocity becomes zero, that is, the so-called no-slip boundary condition in fluid mechanics [24]. Consequently, even though two melted base metals can be thoroughly mixed to become an essentially homogeneous bulk weld pool, a thin layer of melted but unmixed base metal may still exist near each pool boundary. Peninsulas, called "folds", were also observed but not explained [22, 23]. More recently, Kou and Yang [25-30] proposed two mechanisms for the formation of macrosegregation features in dissimilar-filler welding, based on the liquidus temperature of the base metal $T_{L B}$ and that of the weld metal $T_{L W}$. A peninsula or island of the base metal composition can form if $T_{L W}<T_{L B}$ while an irregular-shaped beach of the base metal composition can form if $T_{L W}>T_{L B}$. Both mechanisms were verified in numerous experiments, including welding $\mathrm{Al}$ alloys with various $\mathrm{Al}$ filler metals and welding $\mathrm{Cu}$ with $\mathrm{Cu}$ filler metals of various Ni contents.

In the present study mechanisms for macrosegregation in dissimilar-metal welding will be proposed based on the concepts behind the macrosegregation mechanisms of Kou and Yang 

illustrated in Fig. 1 for the welding of a base metal of liquidus temperature $T_{L B}$. Fig. 1a shows the case of welding without a filler metal. The entire pool boundary is an isotherm at $T_{L B}$ including the solidification front (that is, the trailing portion of the pool boundary) if undercooling is negligible. The resultant weld metal is macroscopically uniform in composition (but microsegregation still exists).

When a dissimilar filler metal is used, it is well mixed in the bulk weld pool. Houldcroft [31] showed in dissimilar-filler welding that the bulk weld metal is uniform in composition due to vigorous mixing in the weld pool. Examples of driving forces for mixing include the Lorentz force and surface-tension gradients along the pool surface $[32,33]$. Fig. 1b shows the case where the composition of the filler metal changes the composition of the bulk weld pool (and hence the composition of the bulk weld metal) such that the liquidus temperature of the bulk weld metal is no longer at $T_{L B}$ but reduced to $T_{L W}$, that is, $T_{L W}<T_{L B}$. Thus, the solidification front of the bulk weld pool shifts backward from $T_{L B}$ to $T_{L W}$. This is because, according to heat flow in welding [34], a lower-temperature isotherm is located farther away from the heat source than a highertemperature one. Thus, the weld pool boundary is no longer isothermal at $T_{L B}$.

As illustrated in Fig. 1b, due to diminishing fluid flow near the pool boundary, a layer of unmixed liquid base metal can exist along the pool boundary, that is, a layer of melted base metal not mixed with the bulk weld pool. The thickness of the layer is exaggerated for clarity of illustration. Since the layer has the same composition as the base metal, it solidifies as a beach of the base metal composition. Thus, the resultant weld metal is no longer uniform in composition. The region of the bulk weld pool ahead of the solidification front is below $T_{L B}$, that is, cooler than the temperature at which liquid base metal can start freezing. Thus, if convection carries the 
melted but unmixed base metal into the cooler bulk weld pool near the solidification front, it can start freezing quickly in to a base-metal-like peninsula or island before it has time to mix with the surrounding bulk weld pool. This can explain why a base-metal-like peninsula can form in the bulk weld pool without mixing with it. Further information is available elsewhere [25-30].

Contrarily, as shown in Fig. 1c, the filler metal changes the composition of the bulk weld pool (and hence the composition of the bulk weld metal) such that the liquidus temperature of the bulk weld metal is no longer at $T_{L B}$ but raised to $T_{L W}$, that is, $T_{L W}>T_{L B}$. Thus, the solidification front of the bulk weld pool shifts forward from $T_{L B}$ to $T_{L W}$. Again, the layer of unmixed liquid base metal solidifies as a beach of the base metal composition. The layer is below $T_{L W}$, that is, cooler than the temperature at which the bulk weld pool can start freezing. Thus, if convection pushes the liquid in the bulk weld pool into this cooler layer, it can start freezing quickly as weld-metal intrusions before it has time to mix with the liquid base metal. The liquid base metal still inside the liquid layer subsequently solidifies as a base-metal-like beach of irregular shape. This can explain why melted base metal in the layer can solidify without mixing with the bulk weld pool and appear highly irregular in shape. Again, further information is available elsewhere [25-30].

\section{Experimental procedure}

To focus on the fundamental understanding of macrosegregation in dissimilar-metal welding, $\mathrm{Cu}$ and steel were selected for welding because the weld metal is essentially a simple binary $\mathrm{Cu}-\mathrm{Fe}$ alloy that can be studied based on the binary $\mathrm{Cu}-\mathrm{Fe}$ phase diagram. The $\mathrm{Cu}$ was a commercially pure $\mathrm{Cu}$ (Grade 110: $\mathrm{Cu}=99 \% ; \mathrm{O}=0.04 \%$ and trace amount of $\mathrm{Ag}$ ) and the steel a low carbon steel, both $1.2 \mathrm{~mm}$ thick, $60 \mathrm{~mm}$ wide and $150 \mathrm{~mm}$ long. 
Gas-tungsten arc welding (GTAW), which is also called tungsten-inert gas (TIG) welding, was selected for the present study. Dissimilar-metal welding of $\mathrm{Cu}$ to steel, stainless steel or pure Fe has been studied by GTAW [10] and by laser- or electron-beam welding [1, 2, 410]. GTAW was selected because fluid flow in the weld pool is simpler, more stable and better understood in GTAW $[32,33]$ than in laser- or electron-beam welding. In laser- and electronbeam welding with a keyhole, the interactions between the vapor pressure, surface tension and gravity can make fluid flow highly unstable and complex. This can make macrosegregation in dissimilar-metal welding more difficult to understand. Also, unlike laser- or electron-beam welding, GTAW is readily accessible. It is of practical interest if dissimilar-metal welds can be made cost effectively.

Butt welding by GTAW was conducted, without a filler metal, in the length direction along the joint with a $1.5 \mathrm{~mm}$ offset of the electrode tip into the $\mathrm{Cu}$ side. The welding conditions were as follows: DC electrode negative (straight polarity), 60 A current, $9.5 \mathrm{~V}$ voltage, $1 \mathrm{~mm} / \mathrm{s}$ travel speed, and $11 \mathrm{~L} / \mathrm{min}$ Ar flow rate. Welding was conducted manually at the travel speed of about $1 \mathrm{~mm} / \mathrm{s}$, with the electrode tip pointed forward in the welding direction and without circular or back-and-forth movement of the torch. Forward welding is common in GTAW, typically with an angle of 60 to $70^{\circ}$ between the electrode and the workpiece. The back side of the workpiece was protected by Ar by mounting the workpiece on a purge box.

The resultant weld was cut normal to the welding direction and polished. The macrograph of the weld was taken after etching it with an acid chloride solution consisting of $20 \mathrm{ml}$ hydrochloric acid $(\mathrm{HCl}), 5 \mathrm{~g}$ ferritic chloride $\left(\mathrm{FeCl}_{3}\right)$ and $100 \mathrm{ml} \mathrm{H}_{2} \mathrm{O}$. It was found that the etching solution dissolved Fe excessively, leaving the Fe-rich phase (dendrites and particles) as deep grooves or pits after etching. Thus, for the composition measurements by electron probe 
microanalysis (EPMA), the weld was re-polished but not etched. As for scanning electron microscopy (SEM), the weld was etched with $3 \%$ Nital. Under SEM, the Fe-rich phase appeared flat and just slightly below the surface of the $\mathrm{Cu}$-rich phase, not as deep grooves or pits. Some composition measurements were also conducted by energy dispersive spectroscopy (EDS) on SEM.

EPMA was performed with a CAMECA SX51 electron probe, operating at $15 \mathrm{kV}$ and 15 nA, with a 25 micron defocused beam, using LIF crystals and P10 gas flow proportional detectors. Counting times were 10 seconds on peak and 10 seconds on backgrounds, with minimal detection limits of 0.04 wt $\%$ for both $\mathrm{Cu}$ and $\mathrm{Fe}$. Pure $\mathrm{Fe}$ and $\mathrm{Cu}$ were used as standards. Matrix corrections were performed with Probe for EPMA software using the PAP algorithm. Composition measurements were made at selected points in the weld. To measure the local average composition at a point, four measurements were made right next to each other to cover a square area of 50 microns by 50 microns, plus one additional measurement at the center of the square. The average of the five measurements was taken as the local average composition at the point of composition measurement. In addition to selected points, composition measurements also were made along a straight line across the entire weld at an interval of 100 microns.

\section{Results and Discussion}

Two mechanisms for macrosegregation in dissimilar-metal welding will be proposed as follows based on the liquidus temperature of the bulk weld metal $T_{L W}$ relative to the liquidus temperature of metal 1 (or alloy 1) $T_{L 1}$ and the liquidus temperature of metal 2 (or alloy 2) $T_{L 2}$. For the purpose of discussion, steel will be considered as metal 1 and $\mathrm{Cu}$ metal 2.

\section{Mechanism I}


Figure 2 shows Mechanism I for the case of $T_{L W}<T_{L 1}$. It is illustrated using the $\mathrm{Cu}-\mathrm{Fe}$ binary phase diagram in Fig. $2 \mathrm{a}$ as an example. $T_{L W}$ is based on the measured composition of the bulk weld metal, which will be shown subsequently in Fig. 5. The plan view of the weld pool is shown in Fig. 2b. As explained previously in Fig. 1, when the bulk weld pool and the base metal differ from each other in composition, the pool boundary is no longer isothermal at the liquidus temperature of the base metal. As illustrated in Fig. 2c, the solidification front of the bulk weld pool is at $T_{L W}$ and that of the layer of unmixed liquid metal 1 is at $T_{L 1}$. When undisturbed by convection, this layer can begin to solidify at $T_{L 1}$ into a beach of base metal 1 . As mentioned previously, a lower-temperature isotherm should be located farther behind the heat source than a higher-temperature one. Thus, since $T_{L W}<T_{L 1}$, the solidification front of the bulk weld pool $T_{L W}$ is shifted backward to behind isotherm $T_{L 1}$.

As shown in Fig. 2c, the region of the bulk weld pool ahead of the solidification front is cooler than $T_{L 1}$, that is, cooler than the temperature at which the liquid metal 1 can start freezing. Thus, as shown in Fig. 2d, when carried backward from the layer of unmixed liquid metal 1 into the cooler region of the bulk weld pool ahead of the solidification front, liquid metal 1 can start to freeze quickly before significant mixing with the surrounding liquid. Since the two liquids are in intimate contact with each other, heat transfer between them is highly effective and thus able to cool liquid metal 1 immediately. Consequently, a peninsula and even an island of metal 1 can form.

It should be noted that fluid flow needs not to be exactly in a horizontal plane in order to form a peninsula. However, it does need to have a component in the backward direction (opposite to the welding direction) in order to be able to carry liquid metal 1 into the cooler region of the bulk weld pool ahead of the solidification front. This is because, if liquid base 
metal 1 is carried forward (in the welding direction) into the bulk weld pool, it will be superheated and thus cannot freeze quickly as a peninsula of unmixed metal 1 (maybe possible as a partially mixed peninsula). Consequently, peninsulas of unmixed metal 1 do not form everywhere along the fusion boundary and may not show up in a weld cross-section taken at a random location along the weld even when they do exist inside the weld. It should also be noted that if the tail of a peninsula is cut normal to the weld, it may appear as an island instead of a peninsula.

\section{Mechanism II}

Figure 3 shows Mechanism II for the case of $T_{L W}>T_{L 2}$. Again, it is illustrated using the $\mathrm{Cu}-\mathrm{Fe}$ binary phase diagram as an example, as shown in Fig. 3a. The plan view of the weld pool is shown in Fig. 3b. Again, the pool boundary is not isothermal as shown in Fig. 3c. The bulk weld pool begins to solidify at $T_{L W}$ (or lower if undercooling occurs) and the layer of unmixed liquid metal 2 begins to solidify at $T_{L 2}$. When undisturbed by convection, this layer can solidify into a beach of base metal 2 .

The effect of convection on macrosegregation is explained in Fig. 3d. The layer of unmixed liquid metal 2 is cooler than $T_{L W}$, that is, cooler than the temperature at which the bulk weld pool can start freezing, as already shown in Fig. 3c. Thus, when the liquid in the bulk weld pool is pushed by convection into this layer, it can start to freeze quickly as intrusions of the bulk weld metal. When the layer of unmixed liquid metal 2 is intruded, some liquid metal 2 can remain in the layer and some gets pushed out into the bulk weld pool. The unmixed liquid metal 2 remaining in the layer can subsequently solidify as a beach of metal 2 that is irregular in shape. Since the liquid metal 2 pushed out of the layer into the bulk weld pool is superheated above its liquidus temperature $T_{L 2}$, it cannot solidify right away. So, it has time to mix with the bulk weld 
pool to become partially mixed metal 2 near the irregular beach of unmixed metal 2 , or even carried away into the bulk weld pool to become partially mixed islands of metal 2 . If $T_{L W} \gg T_{L 2}$, the following features are likely to exist: a thick beach of unmixed metal 2, a thick layer of partially mixed metal 2 near the beach, and large islands of partially mixed metal 2 .

It is perhaps worth pointing out that irregular-shaped beaches caused by Mechanism II are much easier to find in welds than peninsulas caused by Mechanism I. This is because any fluid flow toward the weld pool boundary can result in an irregular-shaped beach. Surfacetension gradients along the weld pool surface, for instance, are known to induce surface flow toward the pool edge [34], which can easily turn toward the pool boundary.

\section{Verification of Mechanisms I and II}

Figure 4 shows optical images taken from the transverse cross-section of a butt weld made between pure $\mathrm{Cu}$ and low carbon steel. The weld specimen was etched with the acid chloride solution mentioned previously. The transverse macrograph in Fig. 4a shows the overall structure of the weld, in which the welding direction is normal to and upward from the macrograph. The dotted lines indicate the fusion boundaries. Three macrosegregation features in the fusion zone can be seen: (i) a peninsula on the steel side, (ii) an irregular-shaped beach on the $\mathrm{Cu}$ side, and (iii) a layered macrostructure in the bulk weld metal, which is a special case for $\mathrm{Cu}$ to-steel welding and thus will be discussed separately subsequently. In Fig. $4 \mathrm{~b}$ the fusion boundary on the $\mathrm{Cu}$ side is revealed by heavy etching. Epitaxial growth of grains from the $\mathrm{Cu}$ base metal into the fusion zone is evident [34]. Along the upper part of the fusion boundary on the steel side, a thin beach about $30 \mu \mathrm{m}$ thick can still be seen at higher magnifications. Before the liquid steel was carried away by convection to form the peninsula, the beach could have been thicker. 

bead-on-plate weld) with a dissimilar filler metal. Macrographs were taken from the vertical longitudinal cross-section along the weld central plane. Peninsulas were observed near the fusion boundary and they always pointed in the opposite direction of welding as suggested by the mechanism proposed for the formation of peninsulas. However, for the fully penetrating butt weld in the present study a similar vertical longitudinal macrograph does not help because the weld bottom does not even have a fusion boundary to allow a peninsula to form. Thus, a transverse macrograph such as that in Fig. 4a is preferred because it at least shows that a peninsula exists.

Fig. 4c shows the microstructure of the peninsula and its surrounding bulk weld metal. Low carbon steel typically does not exhibit a solidification microstructure, neither dendrites nor cells. This is probably because of its very low alloying elements, fast carbon diffusion, and postsolidification phase transformations. Thus, it is not surprising that the peninsula does not have a solidification microstructure to directly confirm that it originated from solidification of a liquid alloy. However, a solid chunk broken off by convection from the steel side that remained unmelted during welding could not possibly have the smooth shape of the peninsula. The numerous dendrites that grow from the peninsula indicate that the melted steel solidified before the surrounding bulk weld pool did. This confirms $T_{L W}<T_{L 1}$.

The results of composition measurements by EPMA are shown in Fig. 5, including the point composition measurements at selected points in the weld metal and the line composition measurements across the entire weld metal. The vertical dotted lines 1 through 8 indicate where the line of composition measurements intersects various boundaries in the microstructure. A Fe- 

fusion zone is essentially $\mathrm{Cu}$-rich, which is consistent with the more $\mathrm{Cu}$ than steel in the fusion zone, caused by the $1.5 \mathrm{~mm}$ offset of the electrode tip into the $\mathrm{Cu}$ side and the much lower melting point of $\mathrm{Cu}$ than steel. The Fe-content profile shows a few peaks, e.g., those indicated by lines 3, 4 and 5 .

As shown by point composition measurements, the peninsula contains $\mathrm{Fe}$ and no $\mathrm{Cu}$, that is, it is steel, unmixed with the surrounding bulk weld metal. This suggests that during welding the melted steel was carried into the adjacent bulk weld pool, which was cooler than the liquidus temperature of steel $T_{L 1}$ and thus caused the liquid steel to freeze quickly before mixing with the bulk weld pool. As shown by point composition measurements, the bulk weld metal surrounding the peninsula has a $\mathrm{Fe}$ content of about 30 to $35 \mathrm{wt} \%$. According to the $\mathrm{Cu}-\mathrm{Fe}$ phase diagram in Fig. 2a, this composition corresponds to a liquidus temperature of about $1425^{\circ} \mathrm{C}$, that is, the liquidus temperature of the bulk weld metal surrounding the peninsula $T_{L W}$ is $1425^{\circ} \mathrm{C}$. Since low carbon steel is close to pure Fe in composition, the liquidus temperature of low carbon steel can be taken as the melting point of pure Fe as an approximation, that is, $T_{L 1}=1538^{\circ} \mathrm{C}$. Thus, the condition of $T_{L W}<T_{L 1}$ for Mechanism I to occur on the steel side of the fusion boundary is verified.

The composition measurements also identify the existence of an irregular beach of $\mathrm{Cu}$, unmixed with the surrounding bulk weld metal. The line composition measurements between vertical dotted lines 1 and 2 show a pure $\mathrm{Cu}$ beach. The point measurement inside the beach also confirms the beach is pure $\mathrm{Cu}$.

As shown by the line composition measurements across the weld, the Fe content of the bulk weld metal ranges from about 22 to 50\%. Thus, according to the phase diagram in Fig. 3a, 
As shown by the optical macrograph in Fig. 4a, the bulk weld metal exhibits a layered structure. Although the two macrosegregation mechanisms discussed above are the main focus of the present study on dissimilar-metal welding, this layered structure of the bulk weld metal still needs to be discussed.

To help explain the layered structure, the $\mathrm{Cu}-\mathrm{Fe}$ phase diagram in Fig. 6 was calculated using the thermodynamic software package Pandat [35] and database PanIron of CompuTherm, LLC [36]. The dotted curved line shortly below the equilibrium liquidus line is the metastable miscibility gap. As mentioned previously, the bulk fusion zone contained significantly more $\mathrm{Cu}$ than steel. Thus, the bulk weld pool (a) can have composition closer to the $\mathrm{Cu}$ side of the phase diagram, for instance, Point $a$. Thus, if the bulk weld pool is undercooled into the miscibility gap during welding, the undercooled bulk weld pool $(b)$ can separate into a $\mathrm{Cu}$-rich liquid phase $(c)$ and a Fe-rich liquid phase $(d)$. Assuming the lever-arm rule, the fraction of the Cu-rich liquid phase is $\underline{b d} / \underline{c d}$, and that of the Fe-rich phase $\underline{c b} \underline{c d}$. Since the $\underline{b d}$ is much larger than $\underline{c b}$, the $\mathrm{Cu}-$ rich liquid phase $(c)$ can be the matrix and the Fe-rich phase $(d)$ spheres in the matrix. This primary separation can be expressed as follows: undercooled bulk weld pool $(b) \rightarrow \mathrm{Cu}$-rich liquid matrix $(c)+$ Fe-rich liquid spheres $(d)$.

Besides primary separation, secondary separation of a $\mathrm{Cu}$-rich liquid from inside the $\mathrm{Fe}$ rich liquid spheres can also occur. Upon further cooling, the Fe-rich liquid spheres $(d)$ can become supersaturated in $\mathrm{Cu}$ at Point $e$ if $\mathrm{Cu}$ diffusion is too slow to let the Fe-rich liquid spheres $(d)$ follow the miscibility gap closely to Point $g$. This $\mathrm{Cu}$ supersaturation can cause $\mathrm{Cu}-$ rich liquid droplets $(f)$ to form from inside the Fe-rich liquid spheres $(e)$. This secondary separation can be expressed as follows: supersaturated Fe-rich liquid spheres $(e) \rightarrow \mathrm{Cu}$-rich liquid droplets $(f)+$ Fe-rich liquid spheres $(g)$. 
$\mathrm{Lu}$ et al. [37] studied the solidification structure of undercooled $\mathrm{Cu}-\mathrm{Fe}$ melts. They induction-melted 8 grams of alloy $\mathrm{Cu}-50 \mathrm{Fe}$ by at $\%$ (or $\mathrm{Cu}-46 \mathrm{Fe}$ by wt\%) in a flux consisting of $70 \% \mathrm{Na}_{2} \mathrm{SiO}_{3}+17.73 \% \mathrm{Na}_{2} \mathrm{~B}_{4} \mathrm{O}_{7}+12.27 \% \mathrm{~B}_{2} \mathrm{O}_{3}$, which let the alloy melt to undercool below the liquidus temperature before solidification started. One undercooled melt solidified into a single layer consisting of Fe-rich spheres dispersed in a $\mathrm{Cu}$-rich matrix. Besides this primary separation, secondary separation of $\mathrm{Cu}$-rich liquid droplets from inside the Fe-rich liquid spheres was also observed.

Based on the lower density of $\mathrm{Fe}(7.86 \mathrm{~g} / \mathrm{cc})$ than $\mathrm{Cu}(8.96 \mathrm{~g} / \mathrm{cc})$, the Fe-rich liquid spheres can be expected to be lighter than the surrounding $\mathrm{Cu}$-rich liquid phase and thus float upward to the top of the $\mathrm{Cu}$-rich liquid phase. As shown by the $\mathrm{Cu}$-Fe phase diagram in Fig. 6, the liquidus line is higher in temperature on the Fe-rich side than the $\mathrm{Cu}$-rich side. This suggests the Fe-rich liquid phase has a larger local undercooling for a given bulk undercooling and hence a larger driving force to nucleate and solidify first [37].

Several different factors might be related to the formation of the layered structure of the weld metal in Fig. 4a. First, the top of the metastable miscibility gap of the $\mathrm{Cu}-\mathrm{Fe}$ phase diagram is only slightly below the liquidus line, so not much supercooling is needed for the weld pool to enter the gap. Second, the cooling rate is fairly fast in arc welding (faster than in casting), fast enough for the bulk weld pool to undercool into the miscibility gap to cause primary separation of Fe-rich liquid spheres from the Cu-rich liquid matrix. The spheres are lighter than the surrounding $\mathrm{Cu}$-rich liquid and can thus float up to its top. Third, the undercooled weld pool could have become significantly more viscous to resist mixing. Viscosity measurements have indicated that liquid metals (and not just glass) become significantly more viscous when 
undercooled [38, 39]. Fourth, horizontal rotational flow can occur in a thin weld pool with an asymmetric current path through the pool $[40,41]$. In the present study, asymmetry might be promoted by the electrode offset to the $\mathrm{Cu}$ side and the much higher electrical conductivity of $\mathrm{Cu}$ than steel. Horizontal rotational flow can stir the viscous bulk weld pool of low depth/width ratio into a layered structure with one layer more or less on top of another, that is, with layers more horizontal than vertical. Each layer can consist of a $\mathrm{Cu}$-rich liquid matrix with Fe-rich liquid spheres at the top.

\section{Microstructure of weld metal}

A series of SEM images of the weld is shown in Fig. 7, with their locations indicated in Fig. 7a. It should be pointed out that Points $b$ through $f$ in Fig. 7a have nothing to do with Points $b$ through $f$ in Fig. 6. Fig. 7b shows the solidification microstructure of the liquid that intrude from the bulk weld pool into the $\mathrm{Cu}$-rich layer at Point $b$. The microstructure consists of very small Fe-rich spheres in a Cu-rich matrix. For comparison, Fig. 7c shows the microstructure of the bulk weld pool nearby at Point $c$ just outside the intruded area. The compositions at these two locations are similar (close to $\mathrm{Cu}-30 \mathrm{Fe}$ according to Fig. 5), but the solidification microstructure is much finer at Point $b$ than at Point $c$. It is well known that the solidification microstructure is finer at a higher cooling rate [42]. Thus, the much finer solidification microstructure at Point $b$ suggests quick freezing of the liquid intruding into the cooler layer of $\mathrm{Cu}$ from the bulk weld pool. According to heat flow in welding [34], the cooling rate is lower at a point farther away from the heat source. Thus, the cooling rate should have been lower at Point $b$ than at Point $c$. This further suggests that the higher cooling rate at Point $b$ was caused by quick freezing. It is worth mentioning that Kou and Yang [25] used a $\mathrm{Cu}-30 \mathrm{Ni}$ filler metal in gas-metal arc welding of pure $\mathrm{Cu}$. The liquid from the bulk weld pool was pushed by convection into the layer of 
melted but unmixed $\mathrm{Cu}$ to freeze quickly as weld-metal intrusions in the pure-Cu beach. The solidification microstructure was much finer in the intrusions than in the nearby bulk weld metal, confirming fast freezing of the intrusion.

Consider the microstructure at Point $d$ in Fig. 7a. For convenience of discussion the layer below Point $d$ will be called the lower layer, the layer above it (all the way to the weld top surface) the upper layer, and the boundary between the two layers the interface. As can be seen in Fig. 7a, dark dots appear to accumulate along the top of the lower layer. As will be shown subsequently, these dark dots are Fe-rich spheres and the material between the dots is the $\mathrm{Cu}$-rich matrix. As mentioned previously, during welding the lighter Fe-rich liquid spheres can float upward to the top of the Cu-rich liquid matrix and accumulate along the interface. Lu et al. [37] also showed Fe-rich spheres floating up to the top of the $\mathrm{Cu}$-rich layer.

Figure 7d shows a SEM image taken at Point $d$. The Fe-rich spheres at the top of the lower layer appear more or less round and about $10 \mu \mathrm{m}$ in diameter, with visible $\mathrm{Cu}$-rich particles inside. The composition measurements by EDS are shown in Fig. 8. Fig. 8a confirms these spheres are Fe-rich and the particles inside are $\mathrm{Cu}$-rich. The Fe-rich spheres consist of a Ferich matrix (about $70 \mathrm{wt} \% \mathrm{Fe}$ at Point 4) and Cu-rich particles (about $7 \mathrm{wt} \% \mathrm{Fe}$ at Point 3). As shown in Fig. 8b, the Fe-rich spheres are surrounded by a Cu-rich phase (about 7 wt\% $\mathrm{Fe}$ at Points 2 and 5), thus indicating Fe-rich liquid spheres floated up to the top of the Cu-rich liquid. As mentioned previously, slow $\mathrm{Cu}$ diffusion can cause the Fe-rich liquid spheres to become supersaturated with $\mathrm{Cu}$ during cooling, thus causing $\mathrm{Cu}$-rich liquid droplets to form inside the Fe-rich liquid spheres (secondary separation). As can be seen in Fig. 7d, the Fe-rich dendrites in the upper layer appear to grow (upward) epitaxially from the Fe-rich spheres at the top of the lower layer. 
particles inside. Since the Fe-rich liquid spheres are lighter than the surrounding Cu-rich liquid, they can float upward during welding.

As for the microstructure at Point $f$ in Fig. 7a, the dark dots at the top of the lower layer are again Fe-rich spheres and the material between the dots is the $\mathrm{Cu}$-rich matrix. These spheres can be seen in the left half of the SEM image shown in Fig. 7f. During welding the lighter Ferich liquid spheres floated up to the top of the lower layer. These Fe-rich liquid spheres appear to have coalesced and contain few $\mathrm{Cu}$-rich particles, suggesting a slower local cooling rate. Again, Fe-rich dendrites in the upper layer appear to grow epitaxially from the Fe-rich spheres.

The line composition measurements in Fig. 5 show peaks of the Fe-content at locations where the line intersects the dark dots, as indicated by vertical dotted lines 3,4 and 5 . These peaks further confirm the dark dots are Fe-rich spheres.

The peninsula and its surroundings have already been shown previously in Fig. 4c. Some Fe-rich liquid spheres floated upward and were stopped by the steel peninsula. Growth of dendrites from the peninsula suggests the melted steel solidified into the peninsula before the surrounding liquid in the bulk weld metal did, consistent with the latter being cooler and causing the former to freeze quickly.

Figure 9 briefly summarizes the discussion so far on macrosegregation in the dissimilarmetal weld between steel (metal 1) and $\mathrm{Cu}$ (metal 2). Fig. 9a shows the formation of the steel peninsula by Mechanism I under the condition of $T_{L W}<T_{L 1}$ and the formation of the irregular $\mathrm{Cu}$ beach by Mechanism II under the condition of $T_{L W}>T_{L 2}$. In the former, the downward flow 
needs to be backward as well in order to carry the melted steel backward into the cooler $\left(T<T_{L 1}\right)$ region ahead of the solidification front to freeze quickly. In the latter, however, the flow only needs to be toward the pool boundary. The two mechanisms can be applied to other dissimilarmetal welding in general, such as steel to stainless steel.

The formation of the layered structure summarized in Fig. $9 \mathrm{~b}$ is related specifically to butt arc welding a thin $\mathrm{Cu}$ sheet to a thin steel (or stainless steel) sheet. The bulk weld pool can undercool into the metastable miscibility gap of the $\mathrm{Cu}-\mathrm{Fe}$ phase diagram to form a Fe-rich liquid phase and a $\mathrm{Cu}$-rich liquid phase, the former as spheres and the latter as the matrix. Since the Fe-rich liquid is lighter than the $\mathrm{Cu}$-rich liquid, the Fe-rich spheres float upward to the top of the $\mathrm{Cu}$-rich liquid. The undercooled bulk weld pool, which is likely viscous, can be stirred by horizontal rotational flow into a layered structure with Fe-rich spheres at the top of each $\mathrm{Cu}$-rich layer.

\section{Macrosegregation in laser- and electron-beam welds}

The above discussion on macrosegregation in the arc weld can help explain macrosegregation in laser- and electron-beam welding of $\mathrm{Cu}$ to steel (or Fe or stainless steel) [2, $5,8]$. The latter can be difficult to understand because fluid flow can be complex in keyhole laser- and electron-beam welding.

First, the existence of very small beaches, peninsulas and islands of steel (or Fe or stainless steel) in the welds can be explained. In keyhole laser- or electron-beam welding of $\mathrm{Cu}$ to steel (metal 1), the condition of $T_{L W}<T_{L 1}$ for the formation of beaches, peninsulas and small islands of unmixed steel also exists. However, these features can be expected to be very small because the layer of unmelted steel tends to be very thin in laser- or electron-beam welding due 
to the very narrow weld pool and very strong convection in the pool. These small macrosegregation features are often not noticed.

Second, the existence of relatively thick beaches of unmixed $\mathrm{Cu}[2,7]$ and irregularshaped $\mathrm{Cu}$ or $\mathrm{Cu}$-rich beaches $[1,2,5,8-10]$ can also be explained. In keyhole laser- or electronbeam welding of $\mathrm{Cu}$ (metal 2) to steel, the condition of $T_{L W}>T_{L 2}$ for the formation of irregularshaped beaches or islands of unmixed $\mathrm{Cu}$ also exists. Due to $T_{L W} \gg T_{L 2}$ and the very high $\mathrm{Cu}$ thermal conductivity, the layer of unmixed liquid $\mathrm{Cu}$ can still be expected to be relatively thick, though thinner than that in arc welding because of the narrow weld pool and strong convection in laser- and electron-beam welding.

Third, the existence of the unusually large $\mathrm{Cu}$-rich islands of irregular shape in the bulk weld metal near the $\mathrm{Cu}$ side $[1,2,5,7-10]$ and even far away from it $[1,7,8]$ can also be explained. Since the cooling rate is very fast in laser- and electron-beam welding, the bulk weld pool itself solidifies rapidly. Thus, the liquid $\mathrm{Cu}$ carried into the bulk weld pool, even if it is unusually large, can also solidify quickly with limited mixing with the bulk weld pool.

Finally, the existence of a layered structure that is more vertical than horizontal in the bulk weld metal can also be explained [1, 5, 7-9]. Under the very high cooling rate in keyhole laser- or electron-beam welding, the weld pool can easily undercool into the miscibility gap of the $\mathrm{Cu}-\mathrm{Fe}$ phase diagram to form two immiscible liquid layers. As mentioned previously, the viscosity of a liquid metal can increase significantly with increasing undercooling. Thus, the undercooled weld pool may be viscous to promote the formation of a layered structure in the weld pool. The high cooling rate can help the layered liquids solidify before being dispersed. The depth/width ratio of the weld pool is much greater in keyhole laser- and electron-beam welding than in arc welding. Thus, as compared to arc welding of thin sheets (Fig. 4a), the flow loop in 
the weld pool can be more vertical even near the top surface of the weld pool, where the loop can be shallower due to influence by flow driven by surface-tension gradients. The layered structure often showed relatively thick $\mathrm{Cu}$-rich bands near the weld top surface on the $\mathrm{Cu}$ side, where melting of $\mathrm{Cu}$ was most intensive. It is interesting that an onion-ring structure, wider in the vertical direction than horizontal, was observed deep below the weld top surface [5]. As in arc welding, spheres of one phase in the matrix of another can be expected and, in fact, have been observed $[1,2,5,8-10]$.

\section{Welding stainless steels dissimilar in sulfur content}

A 304L stainless steel with $0.003 \mathrm{wt} \% \mathrm{~S}$ has been butt welded to a 303 stainless steel with $0.293 \mathrm{wt} \% \mathrm{~S}$, both with about $18 \mathrm{wt} \% \mathrm{Cr}$ and 8 wt $\% \mathrm{Ni}$ [42-44]. It was observed in both gas-tungsten arc welding and conduction-mode laser-beam welding that the low-S stainless steel (304L) melted to a significantly greater extent than the high-S one (303). Sulfur, S, is known to be a surface-active agent in steels and stainless steels. Increasing the $\mathrm{S}$ content can change $d \gamma / d T$ from negative to positive and hence reverse the direction of surface-tension driven flow, where $\gamma$ is surface tension and $T$ temperature [34]. Detailed computer simulation of heat transfer, fluid flow and mass transfer was conducted. The lateral shift of the weld pool from the original joint interface (toward the low-S one) and the rotation of the weld pool at an angle with the interface were both explained. Since the liquidus temperature is hardly affected by $S$ at these low concentration levels, the special situation of $T_{L W}=T_{L 1}=T_{L 2}$ can exist. However, since both stainless steels contained about $18 \mathrm{wt} \% \mathrm{Cr}$ and $8 \mathrm{wt} \% \mathrm{Ni}$, no significant macrosegregation of $\mathrm{Cr}$ or Ni was observed. For significant macrosegregation to occur, the two materials needs to differ significantly in the contents of major alloying elements (such as $\mathrm{Cr}$ and $\mathrm{Ni}$ ) and hence in the liquidus temperature as explained in the present study. 


\section{Conclusions}

1. Two mechanisms of macrosegregation in dissimilar-metal fusion welding have been proposed to explain the formation of macrosegregation features based on the liquidus temperature of the bulk weld metal $T_{L W}$ relative to those of metal 1 (or alloy 1) $T_{L 1}$ and metal 2 (or alloy 2) $T_{L 2}$.

2. Mechanism 1 is for the case of $T_{L W}<T_{L 1}$, and it can explain the formation of peninsulas or islands as well as beaches of unmixed metal 1.

3. Mechanism 2 is for the case of $T_{L W}>T_{L 2}$, and it can explain why the beaches of unmixed metal 2 can form with an irregular shape.

4. These two mechanisms have been verified in arc welding of $\mathrm{Cu}$ (metal 2) to steel (metal 1) by the formation of a peninsula of unmixed steel and an irregular-shaped beach of unmixed $\mathrm{Cu}$. A thick liquid layer of unmixed $\mathrm{Cu}$ can exist next to $\mathrm{Cu}$ because of two reasons: (i) the much lower melting point of $\mathrm{Cu}$ than steel, i.e., $T_{L W}>>T_{L 2}$, and (ii) the very high thermal conductivity of $\mathrm{Cu}$.

5. A layered structure, with layers more horizontal than vertical, has been observed in the bulk weld metal. It is caused by undercooling of the bulk weld pool into a metastable miscibility gap in the $\mathrm{Cu}-\mathrm{Fe}$ phase diagram and possibly promoted by horizontal rotational flow in the weld pool, which has a low depth/width ratio.

6. In laser- or electron-beam welding, a relatively thick liquid layer of unmixed $\mathrm{Cu}$ can also exist next to $\mathrm{Cu}$ for the same reasons as in arc welding. However, when swept far away by convection, liquid $\mathrm{Cu}$ can still solidify as large $\mathrm{Cu}$-rich islands (instead of mixing into the bulk weld pool) because the bulk weld pool itself can solidify very fast. A layered 
structure can also form because of the same reasons as in arc welding, but more vertical than horizontal because of the deep and narrow weld pool associated with the keyhole.

\section{Acknowledgements}

The authors would like to thank CompuTherm, LLC in Madison, WI for kindly providing Pandat 2013 and PanIron 2013 for calculating the $\mathrm{Cu}$-Fe phase diagram and Dr. Chuang Zhang of CompuTherm for assistance in the miscibility gap calculation. They are grateful to Dr. John H. Fournelle of the Department of Geoscience, UW-Madison for composition measurements by EPMA. They would also like to thank Dr. Ping Yu for helpful discussions on the weld microstructure. This work was supported by the National Science Foundation under Grant No. DMR 1500367.

\section{References}

1. S. Chen, J. Huang, J. Xia, H. Zhang and X. Zhao, "Microstructural Characteristics of a Stainless Steel/Copper dissimilar joint by laser welding”, Metallurgical and Materials Transactions A, 44a (2013) 3690-3696.

2. I. Magnabosco, P. Ferro, F. Bonollo, L. Arnberg, "An investigation of fusion zone microstructures in electron beam welding of copper-stainless steel”, Materials Science and Engineering A 424 (2006) 163-173.

3. S. Asai, T. Ogawa, Y. Ishizaki, T. Minemura, H. Minami and S. Miyazaki, "Application of plasma MIG hybrid welding to dissimilar joints between copper and steel”, No. 02 2012, vol. 56, Welding in the World, pp. 37-42. 
4. T. A. Mai, A.C. Spowage, "Characterisation of dissimilar joints in laser welding of steelkovar, copper-steel and copper-aluminium”, Materials Science and Engineering A 374 (2004) 224-233.

5. G. Phanikumar, S. Manjini, P. Dutta, J. Mazumder, K. Chattopadhyay, Characterization of a continuous $\mathrm{CO}_{2}$ laser-welded $\mathrm{Fe}-\mathrm{Cu}$ dissimilar couple. Metall. Mater. Trans. A 36 (2005) 2137-2147.

6. B. Zhang, J. Zhao, X. Li, and G. Chen, "Effects of filler wire on residual stress in electron beam welded QCr0.8 copper alloy to 304 stainless steel joints", Applied Thermal Engineering 80 (2015) 261-268.

7. B. Zhang, J. Zhao, X. Li, J. Feng, "Electron beam welding of 304 stainless steel to QCr0.8 copper alloy with $\mathrm{Cu}$ filler wire”, Trans. Nonferrous Met. Soc. China 24(2014) 4059-4066.

8. S. Chen, J. Huang, J. Xia, X. Zhao, S. Lin, "Influence of processing parameters on the characteristics of stainless steel-copper laser welding”, Journal of Materials Processing Technology 222 (2015) 43-51.

9. C. Yao, B. Xu, X. Zhang, J. Huang, J. Fu, Y. Wu, "Interface microstructure and mechanical properties of laser welding copper-steel dissimilar joint", Optics and Lasers in Engineering 47 (2009) 807-814.

10. A. Munitz, 1995. "Metastable liquid phase separation in tungsten inert gas and electron beam copper-stainless-steel welds", Journal of Materials Science 30(1995) 2901-2910. 
11. T. Doody: "Intermediate mixed zones in dissimilar metal welds for sour service," Welding Journal, 61: 55-60, 1992.

12. A. A. Omar: "Effects of welding parameters on hard zone formation at dissimilar metal welds," Welding Journal, 67: 86s-93s, 1998.

13. R. Dehmolaei, M. Shamanian, A. Kermanpur, "Effect of electromagnetic vibration on the unmixed zone formation in $25 \mathrm{Cr}-35 \mathrm{Ni}$ heat resistant steel/alloy 800 dissimilar welds", Materials Characterization 59(2008) 1814-1817.

14. H. Naffakh, M. Shamanian, F. Ashrafizadeh, Journal of Materials Processing Technology 209(2009) 3628-3639.

15. G. E. Linnert: Welding Metallurgy, vol. 2. American Welding Society, Miami, 1967.

16. W. F. Savage, E. F. Nippes, and E. S. Szekeres: "Hydrogen induced cold cracking in a low alloy steel,” Welding Journal, 55: 276s-283s, 1976.

17. M. D. Rowe, T. W. Nelson, and J. C. Lippold: "Hydrogen-induced cracking along the fusion boundary of dissimilar metal welds," Welding Journal, 78: 31s-37s, 1999.

18. H. Cordier, M. Schippers, and I. Polmear: "Microstructure and intercrystalline fracture in a weldable aluminum-zinc-magnesium alloy,” Z. Metallkde, 68: 280-284, 1977.

19. M. Pirner, and H. Bichsel, "Corrosion resistance of welded joints in AlZnMg," Metall, 29: $275-280,1975$.

20. W. A. Baeslack III, J. C. Lippold, and W. F. Savage: "Unmixed zone formation in austenitic stainless steel weldments," Welding Journal, 58: 168s-176s, 1979.

21. K. G. Kent: Metals and Materials, "Weldable Al-Zn-Mg alloys,” 4: 429-440, 1970. 
22. W. F. Savage and E. S. Szekeres: "A mechanism for crack formation in HY-80 steel weldments,” Welding Journal, 46: 94s-96s, 1967.

23. W. F. Savage, E. F. Nippes and E. S. Szekeres: "A study of fusion boundary phenomena in a low alloy steel," Welding Journal, 55: 260s-268s, 1976.

24. S. Kou: Transport Phenomena and Materials Processing, John Wiley and Sons, New York, NY, 1996, pp. 57-60.

25. S. Kou and Y. K. Yang, "Fusion-Boundary Macrosegregation in Dissimilar-Filler Welds", Welding Journal, vol. 86, 2007, pp. 303s to 312s.

26. Y. Yang and S. Kou, "Macrosegregation in Al-Si Welds Made with Dissimilar Filler Metals", Science and Technology of Welding and Joining, vol. 15, No. 1, 2010, pp. 1-14.

27. Y. K. Yang and S. Kou, "Macrosegregation Mechanisms in Arc Welds Made with Dissimilar Filler Metals", Science and Technology of Welding and Joining, vol. 15, No. 1, 2010, pp. 15-30.

28. Y. Yang and S. Kou, "Macrosegregation in Cu-30Ni Welds Made with Dissimilar Filler Metals", Science and Technology of Welding and Joining, vol. 13, No. 4, 2008, pp. 318326.

29. Y. K. Yang and S. Kou, "Fusion-Boundary Macrosegregation in Dissimilar-Filler Al-Cu Welds", Welding Journal, vol. 86, 2007, pp. 331s to 339s.

30. Y. K. Yang and S. Kou, "Weld-Bottom Macrosegregation Caused by Dissimilar Filler Metals, Welding Journal, vol. 86, 2007, pp. 379s to 387s. 
31. R. T. Houldcroft: "Dilution and uniformity in aluminum alloy weld beads," British Welding Journal, 1: 468-472, 1954.

32. S. Kou and D. K. Sun: "Fluid Flow and Weld Penetration in Stationary Arc Welds", Metallurgical Transactions A, vol. 16A, 1985, p. 203.

33. S. Kou and Y. H. Wang: "Computer Simulation of Convection in Moving Arc Weld Pools", Metallurgical Transactions A, vol. 17A, 1986, p. 2271.

34. S. Kou: Welding Metallurgy, 2nd ed., Wiley, New York, NY, 2003, pp. 114, 180, 206, 208 and 306.

35. Pandat - Phase Diagram Calculation software package for Multicomponent Systems, Computherm LLC, Madison, WI 53719, 2013.

36. PanIron - Thermodynamic database for Commercial Aluminum Alloys, Computherm LLC, Madison, WI 53719, 2013.

37. X. Y. Lu, C. D. Cao, B. Wei, Microstructure evolution of undercooled iron-copper hypoperitectic alloy, Materials Science and Engineering A313 (2001) 198-206.

38. P.-F. Paradis, T. Ishikawa and S. Yoda, Surface tension and viscosity of liquid and undercooled tantalum measured by a containerless method", Journal of Applied Physics 97, 053506 (2005).

39. P.-F. Paradis, T. Ishikawa and S. Yoda, Viscosity of liquid undercooled tungsten, Journal of Applied Physics 97, 106101 (2005).

40. R. A. Woods and D. R. Milner, Motion in the weld pool in arc welding, Welding Journal, vol. 50, 1971, pp. 163s-173s. 
41. W. H. S. Lawson and H. W. Kerr, Fluid motion in GTA weld pools, Part 1: flow patterns and weld pool homogeneity, Welding Research International, volume 6, 1976, number 5, pp. 63-77.

42. M. C. Flemings, Solidification Processing, McGraw-Hill, New York, 1974.

43. S. Mishra, T. J. Lienert, M. Q. Johnson, T. DebRoy, An experimental and theoretical study of gas tungsten arc welding of stainless steel plates with different sulfur concentrations, Acta Materialia 56 (2008) 2133-2146.

44. T. J. Lienert, P. Burgardt, K. L. Harada, R.T. Forsyth and T. DebRoy, Weld bead center line shift during laser welding of austenitic stainless steels with different sulfur content, Scripta Materialia 71 (2014) 37-40.

45. H. L. Wei, S. Pal, V. Manvatkar, T. J. Lienert, T. DebRoy, Asymmetry in steel welds with dissimilar amounts of sulfur, Scripta Materialia 108 (2015) 88-91.

\section{Figure Captions}

Fig. 1 Dissimilar-filler welding concepts of Kou and Yang [25-30] (to be applied to dissimilarmetal welding) showing solidification front: (a) at $T_{L B}$; (b) shifted backward by dissimilar filler to $T_{L W}\left(<T_{L B}\right)$; (c) shifted forward by dissimilar filler to $T_{L W}\left(>T_{L B}\right)$. Filler metal changes composition and hence liquidus temperature of bulk weld metal. Pool boundary (thick blue line) is no longer isothermal with dissimilar filler.

Fig. 2 Mechanism I for macrosegregation in dissimilar-metal welding under the condition of $T_{L W}$ $<T_{L 1}$ : (a) phase diagram of $\mathrm{Cu}-\mathrm{Fe}$ as an example; (b) plan view of weld pool and its surroundings; (c) formation of beach alone; (d) formation of peninsula and island as well 
as beach. $T_{L W}$ is based on the measured composition of the bulk weld metal (shown subsequently in Fig. 5).

Fig. 3 Mechanism II for macrosegregation in dissimilar-metal welding under the condition of $T_{L W}>T_{L 2}$ : (a) phase diagram of $\mathrm{Cu}-\mathrm{Fe}$ as an example; (b) plan view of weld pool and its surroundings; (c) formation of smooth beach; (d) formation of beach of irregular shape.

Fig. 4 Transverse macrograph of $\mathrm{Cu}$-to-steel arc weld: (a) overall structure; (b) fusion boundary (indicated by arrowheads) on $\mathrm{Cu}$ side and $\mathrm{Cu}$ beach of irregular shape; (c) steel peninsula and its surrounding microstructure.

Fig. 5 Composition measurements by EPMA at various locations inside the weld and along a horizontal straight line across the weld. The peak Fe contents at lines 3, 4 and 5 are associated with the intersections between the horizontal straight line and dark dots (Ferich spheres).

Fig. $6 \mathrm{Cu}-\mathrm{Fe}$ phase diagram calculated using thermodynamic software Pandat [35] and database PanIron [36] of CompuTherm, LLC. Primary separation: undercooled bulk weld pool (b) $\rightarrow$ Cu-rich matrix (c) + Fe-rich spheres (d). Secondary separation: Fe-rich spheres supersaturated with $\mathrm{Cu}(\mathrm{e}) \rightarrow$ Cu-rich liquid droplets (f) + Fe-rich spheres (g).

Fig. 7 Microstructure of $\mathrm{Cu}$-steel arc weld: (a) optical micrograph showing locations of SEM images in fusion zone; (b) - (f) SEM images.

Fig. 8 SEM image in Fig. 7d (Point d) enlarged: (a) composition measurements by EDS; (b) schematic sketch of microstructure around Points 3 through 5 during welding.

Fig. 9 Summary of segregation features in dissimilar-metal welding revealed with the help of arc welding $\mathrm{Cu}$ (metal 2) to steel (metal 1): (a) formation of peninsula under the condition of 
$T_{L W}<T_{L 1}$ and irregular beach under $T_{L W}>T_{L 2}$; (b) formation of layered weld-metal structure. 


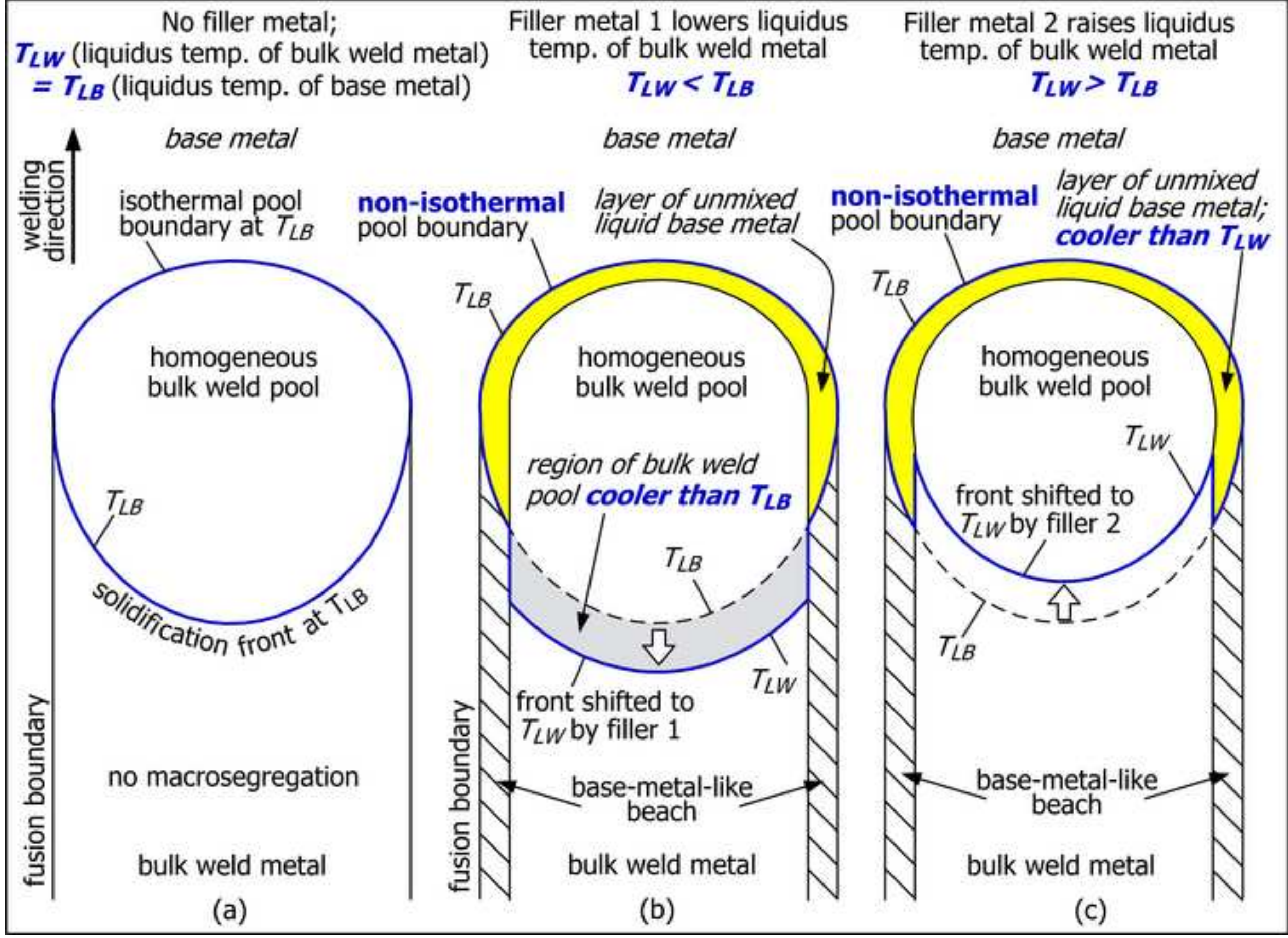




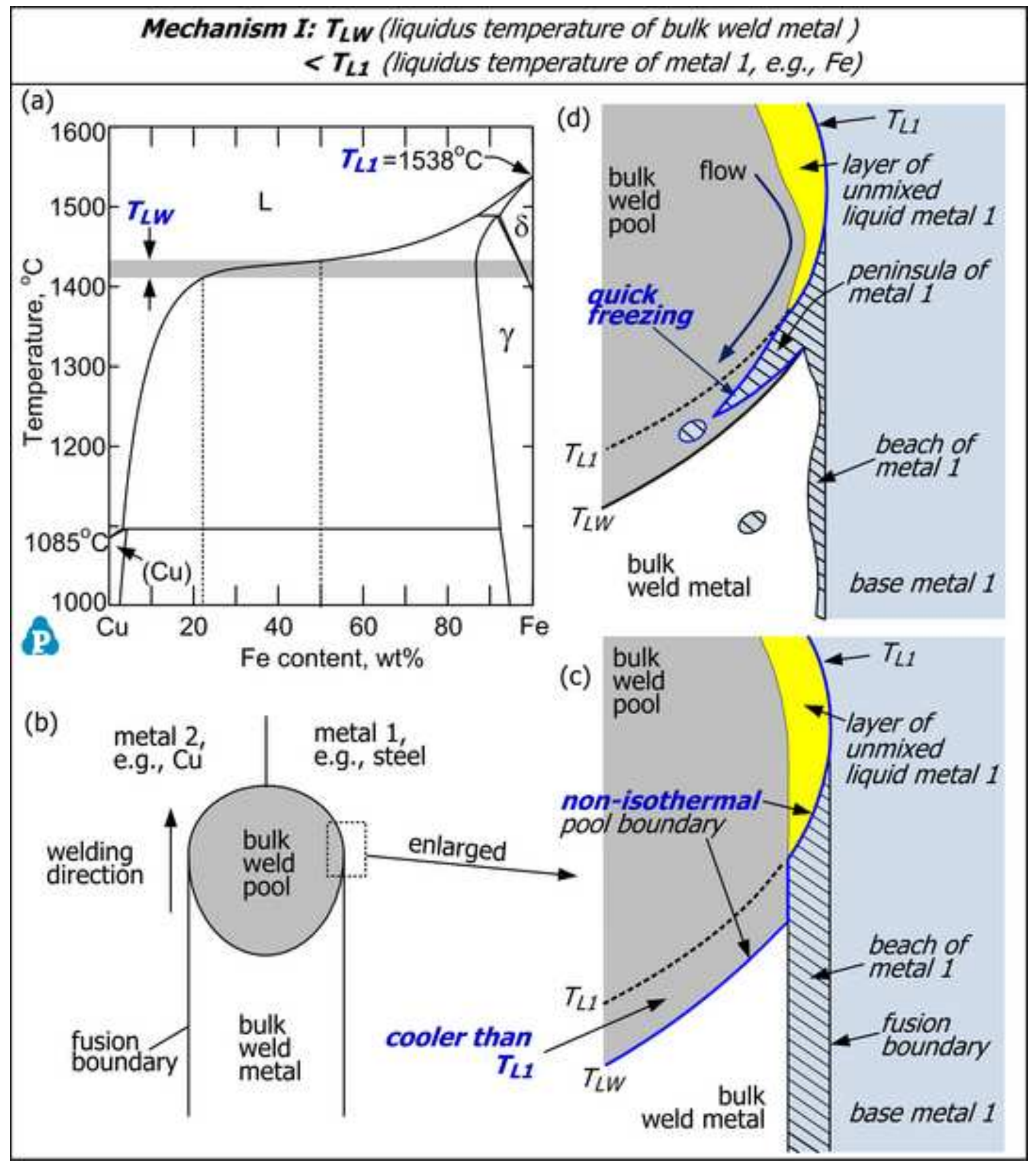




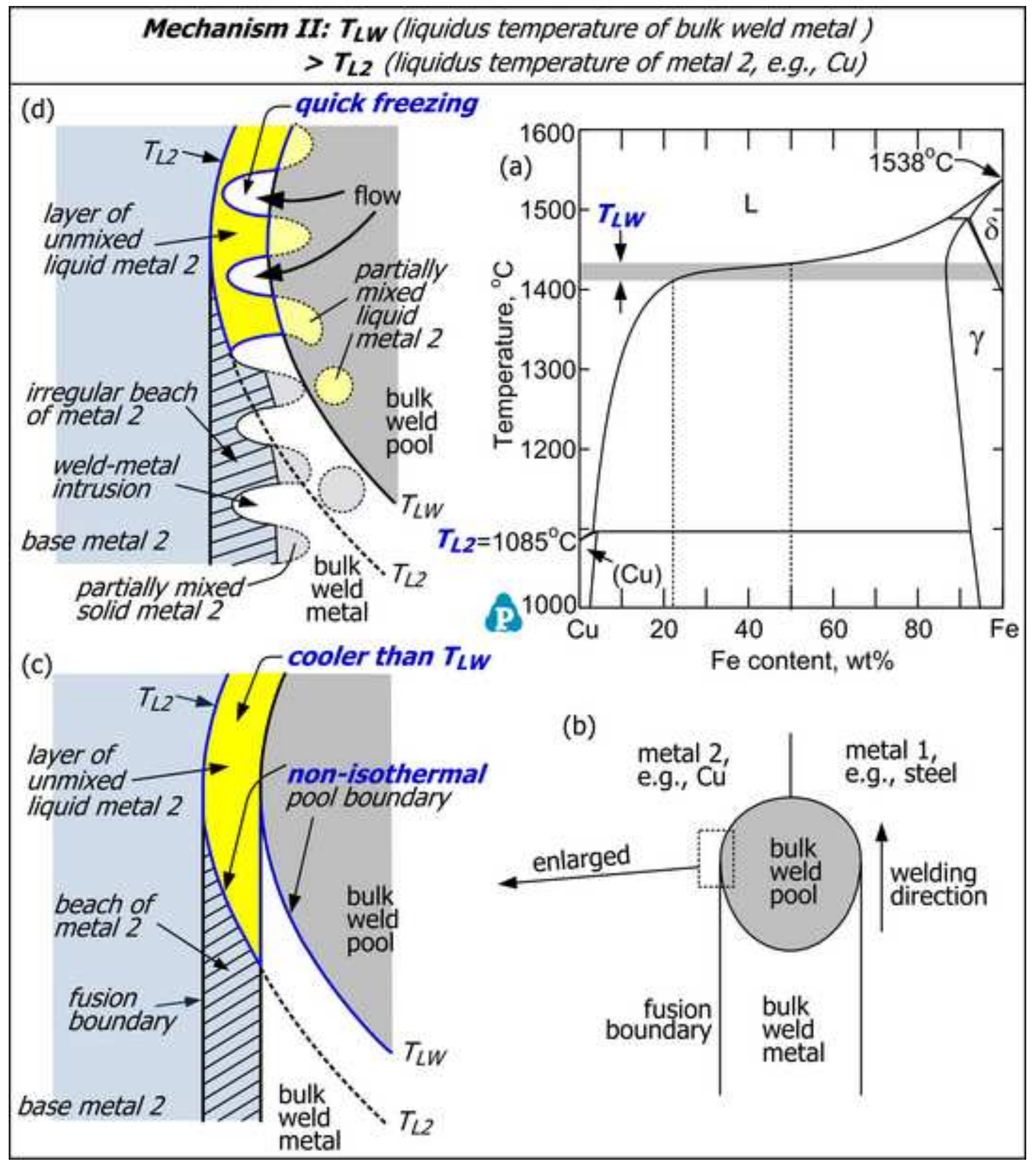




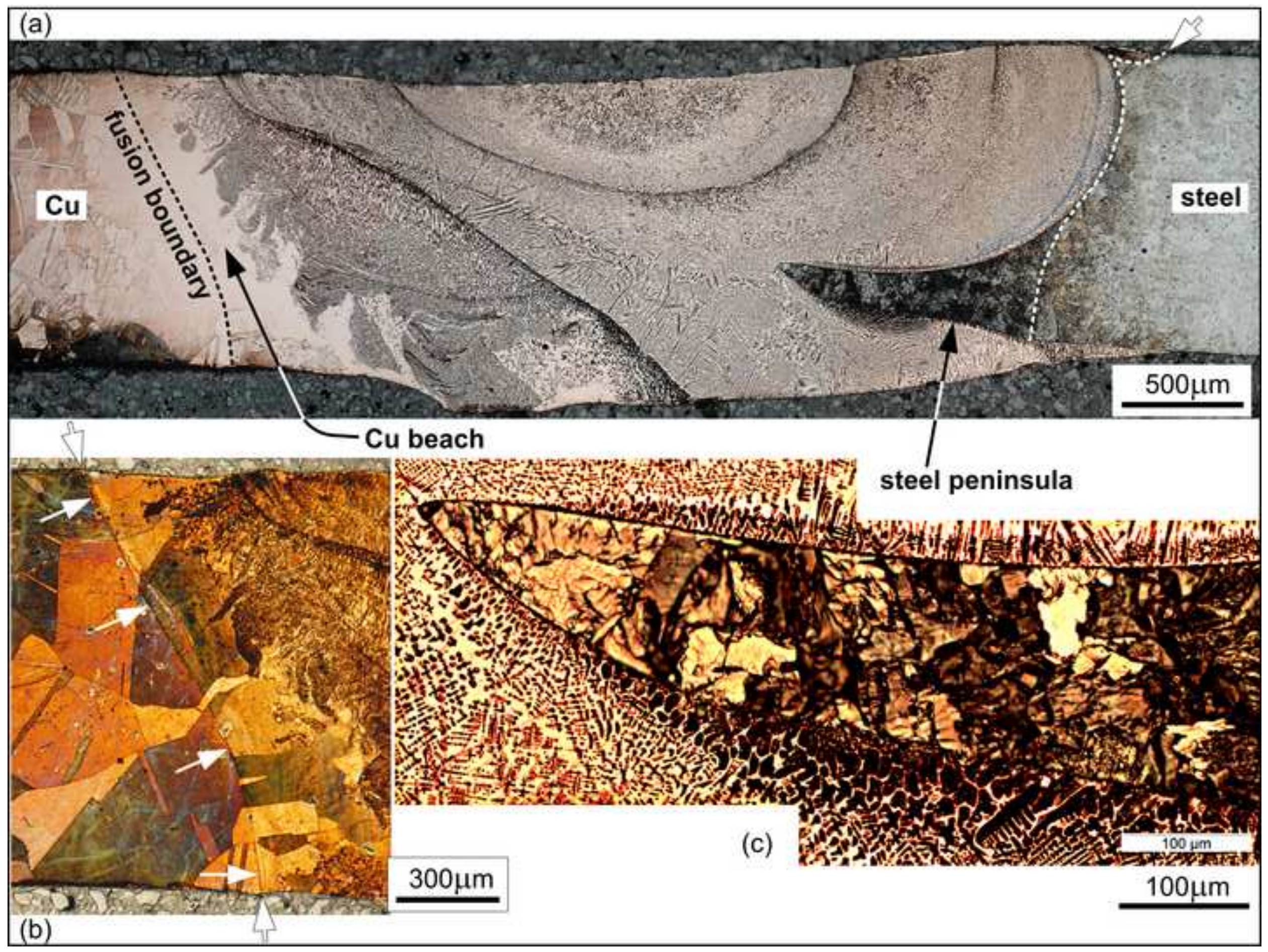




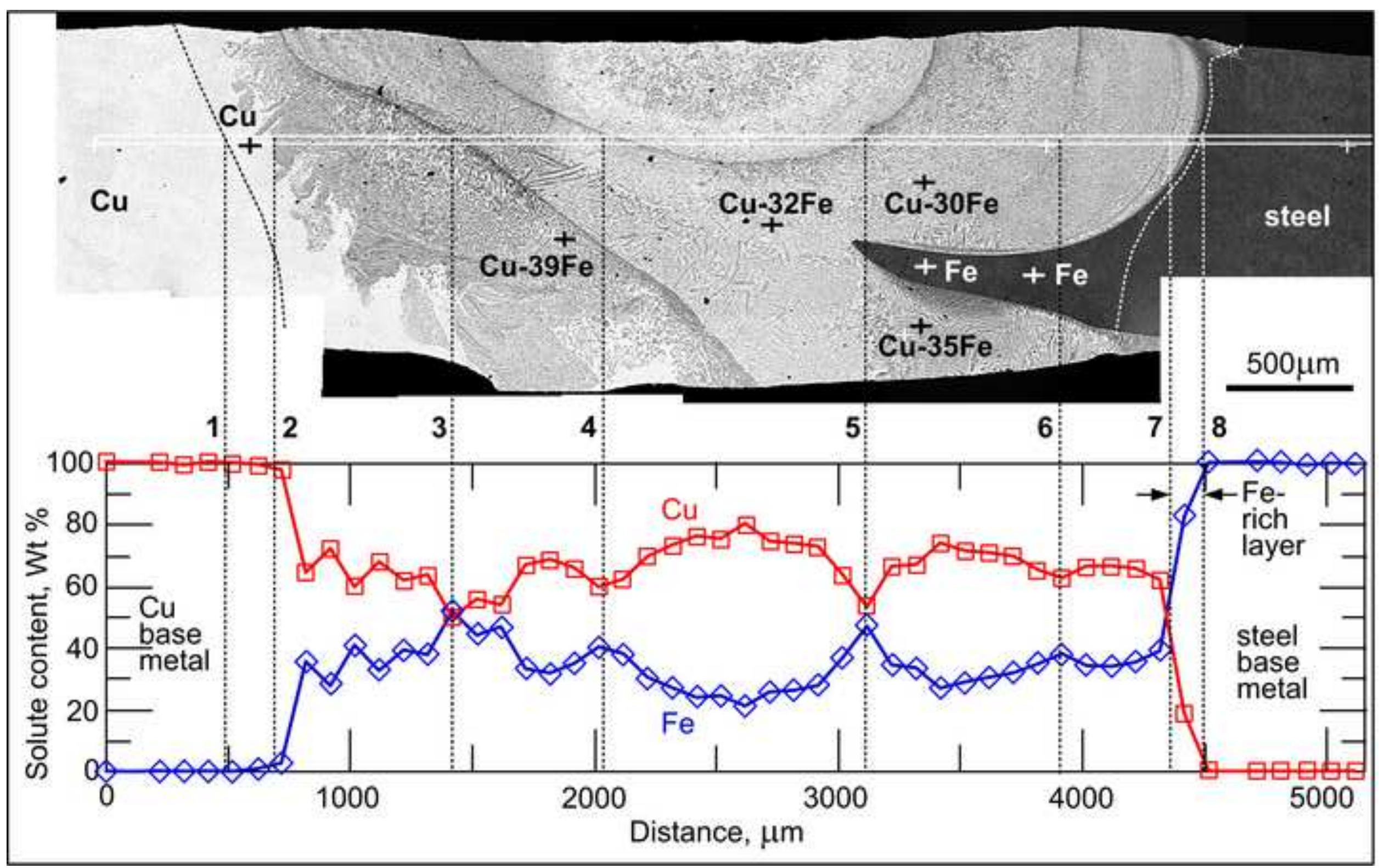




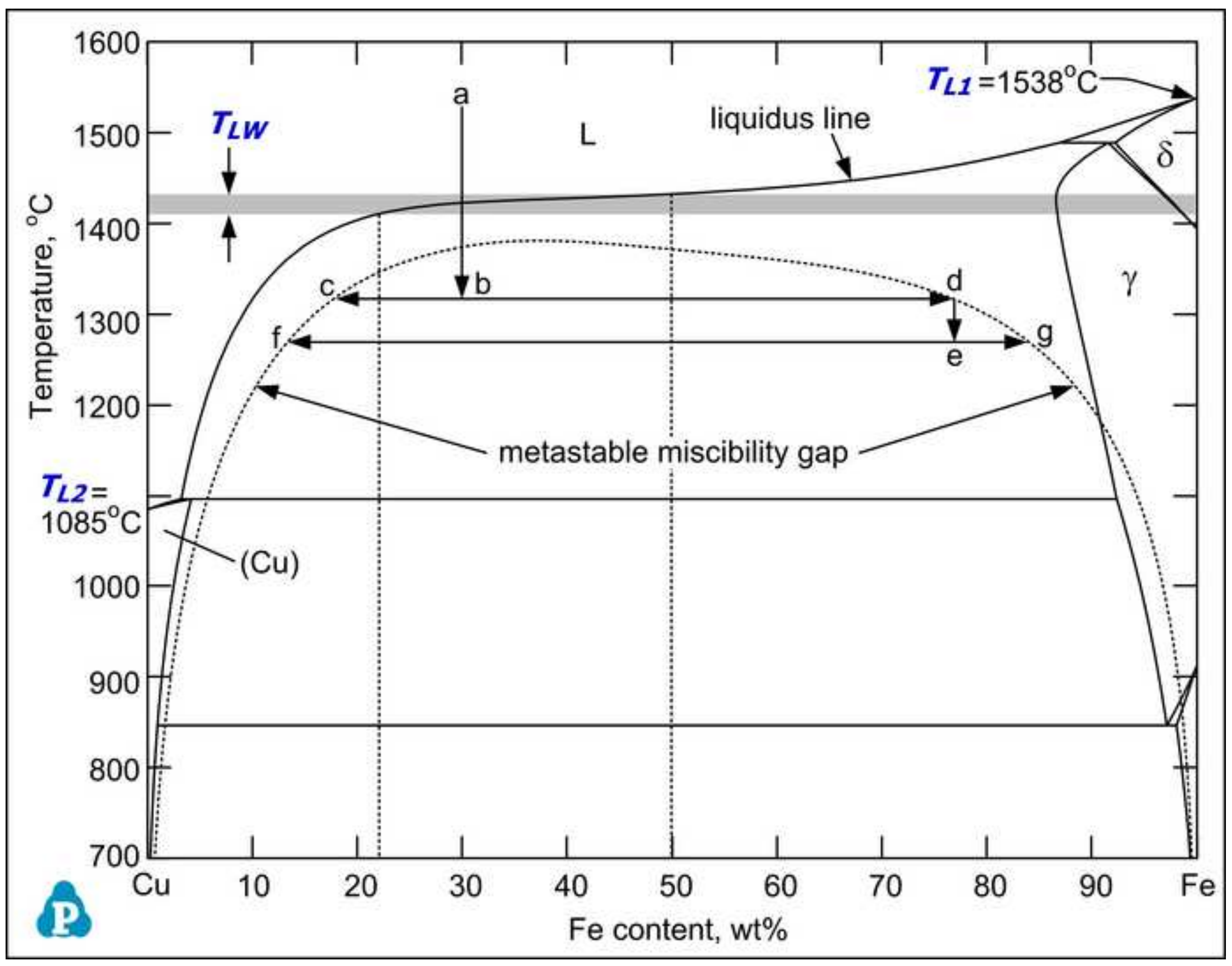




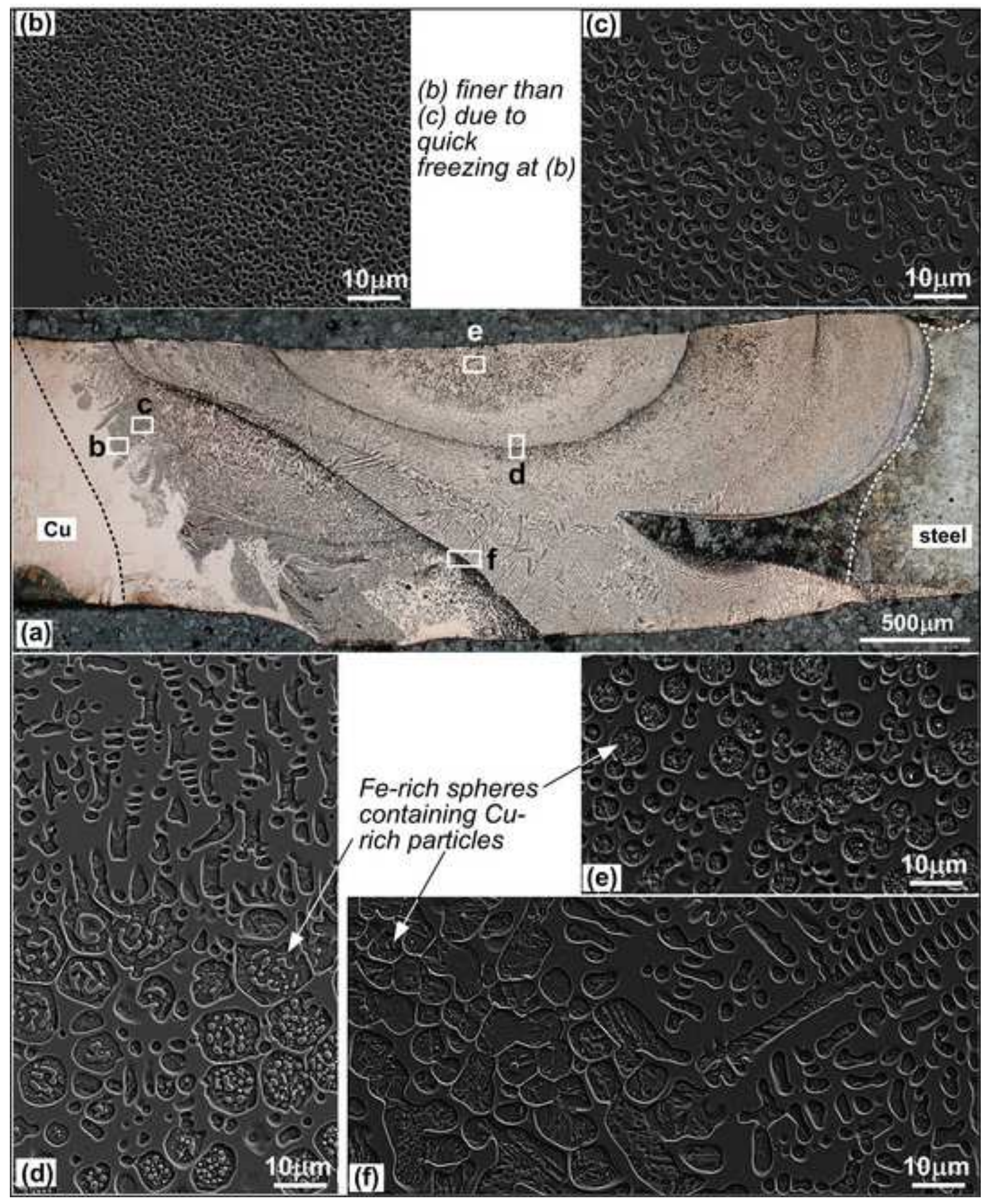




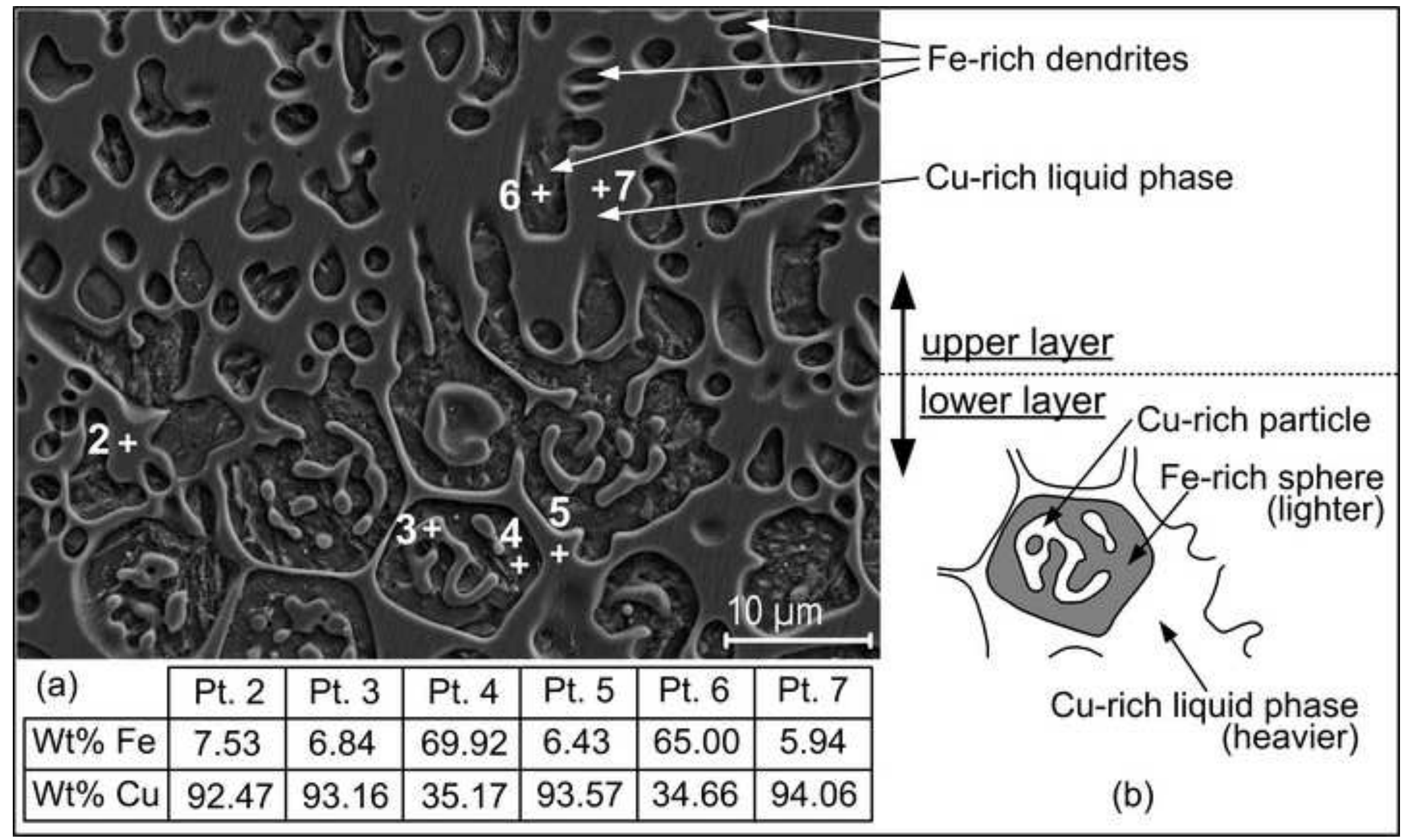




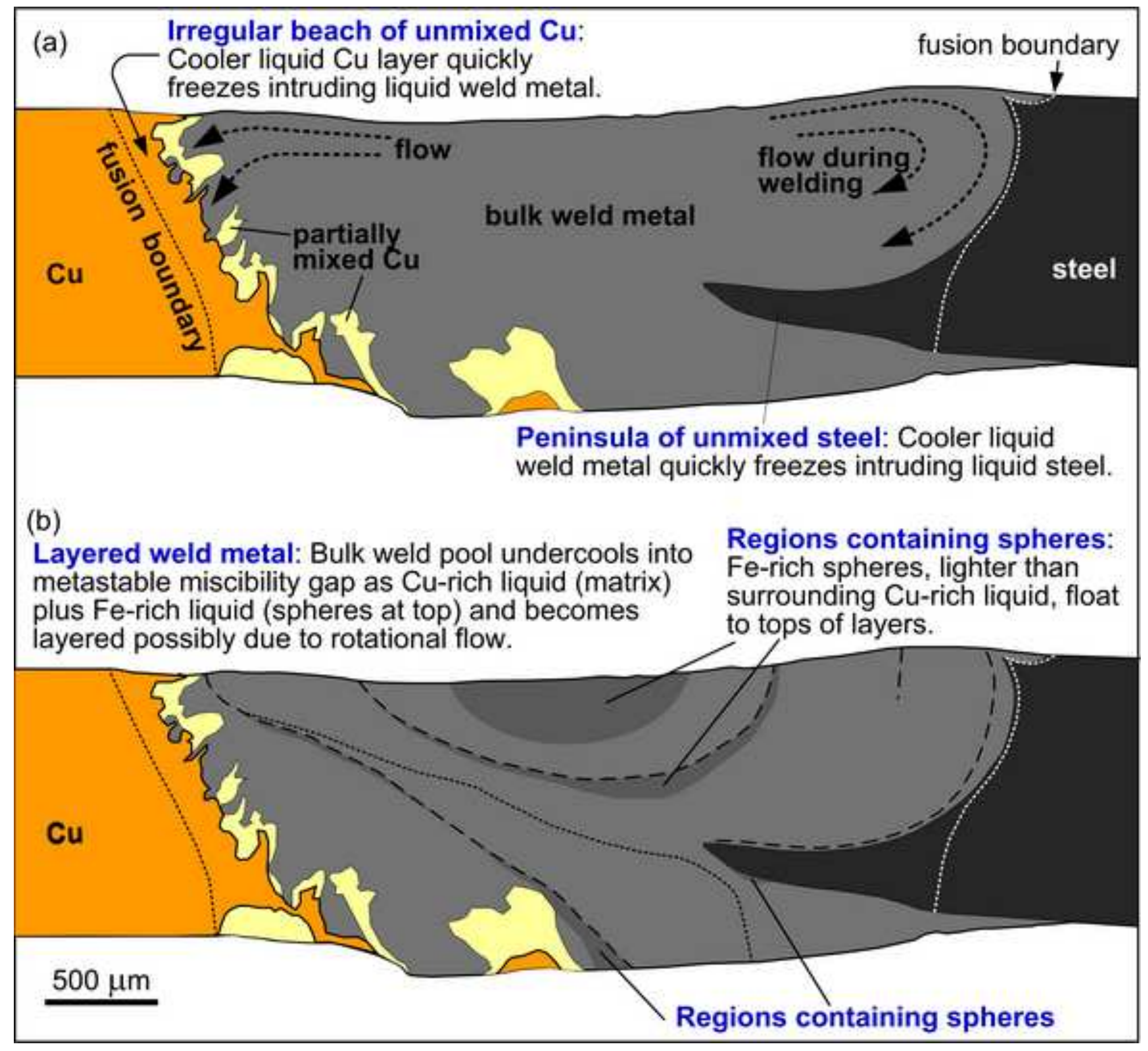


Graphic Abstract Solute segregation across a weld between two dissimilar metals or alloys has long been recognized, but fundamental understanding is still lacking. Two macrosegregation mechanisms were proposed based on the liquidus temperature of the bulk weld metal $T_{L W}$ relative to those of metal 1 (or alloy 1) $T_{L 1}$ and metal 2 (or alloy 2) $T_{L 2}$. A "peninsula" of an unmixed metal $1 \mathrm{can}$ form if $T_{L W}<T_{L 1}$, while a "beach" of unmixed metal 2 irregular in shape can form if $T_{L W}>T_{L 2}$. The mechanisms were verified in Cu-to-steel arc welding. The bulk weld metal showed a layered structure caused by undercooling of the bulk weld pool into a metastable miscibility gap in the $\mathrm{Cu}-\mathrm{Fe}$ phase diagram. These findings were used to explain macrosegregation observed in laser- and electron-beam welding of $\mathrm{Cu}$ to steel or stainless steel.

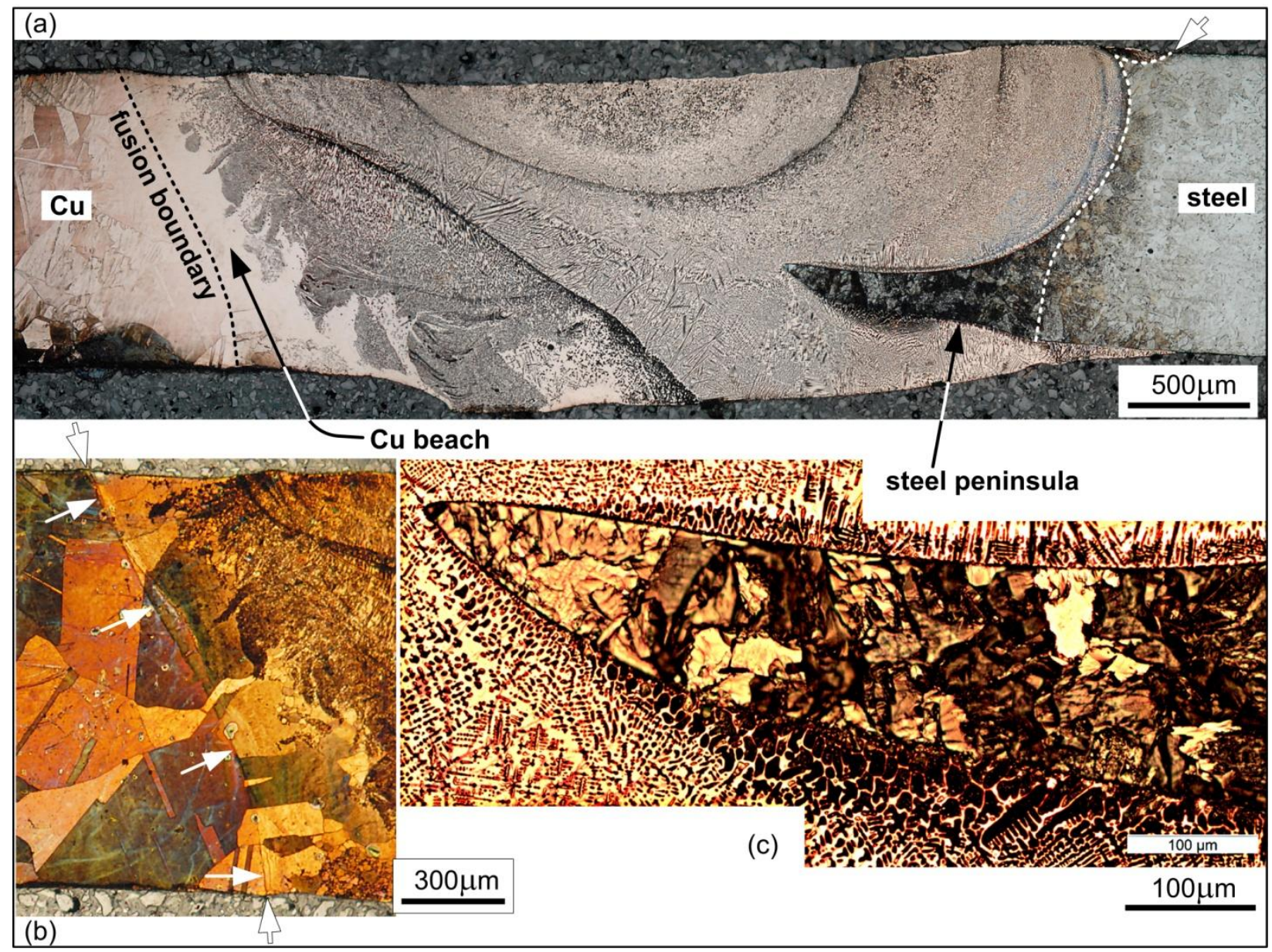

Transverse macrograph of Cu-to-steel arc weld showing three macrosegregation features: a steel peninsula (right), an irregular-shape $\mathrm{Cu}$ beach (left) and a layered weld metal (bulk fusion zone). 